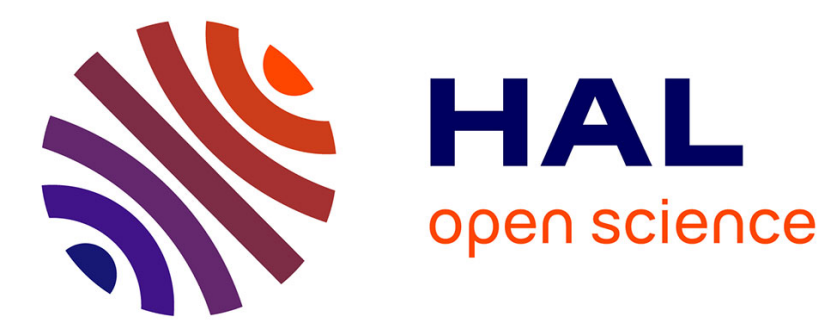

\title{
Self-Discharge Characterization and Modeling of Electrochemical Capacitor Used for Power Electronics Applications
}

\author{
Yasser Diab, Pascal Venet, Hamid Gualous, Gérard Rojat
}

\section{- To cite this version:}

Yasser Diab, Pascal Venet, Hamid Gualous, Gérard Rojat. Self-Discharge Characterization and Modeling of Electrochemical Capacitor Used for Power Electronics Applications. IEEE Transactions on Power Electronics, 2009, 24 (2), pp.510 - 517. 10.1109/TPEL.2008.2007116 . hal-00368848

\section{HAL Id: hal-00368848 https://hal.science/hal-00368848}

Submitted on 3 Jun 2009

HAL is a multi-disciplinary open access archive for the deposit and dissemination of scientific research documents, whether they are published or not. The documents may come from teaching and research institutions in France or abroad, or from public or private research centers.
L'archive ouverte pluridisciplinaire HAL, est destinée au dépôt et à la diffusion de documents scientifiques de niveau recherche, publiés ou non, émanant des établissements d'enseignement et de recherche français ou étrangers, des laboratoires publics ou privés. 


\title{
Self-Discharge Characterization and Modeling of Electrochemical Capacitor Used for Power Electronics Applications
}

\author{
Yasser Diab, Pascal Venet, Hamid Gualous, and Gérard Rojat
}

\begin{abstract}
The self-discharge of an electrochemical capacitor, also referred to as a supercapacitor, is an important factor in determining the duration of maintaining stored energy, especially in low-duty-cycle applications. The study of self-discharge is conducted as follows: first, the self-discharge is characterized by measuring the decline of open-circuit voltage of the electrochemical capacitor. Second, the mechanisms of self-discharge, leakage current, and diffusion of ions at the electrode-electrolyte interfaces are modeled by an electrical equivalent circuit. The equivalent circuit elements are experimentally determined according to the self-discharge time behavior. In addition, the dependence of the self-discharge parameters on both temperature and initial voltage across the electrochemical capacitor is described in detail.
\end{abstract}

Index Terms-Electrochemical capacitor, self-discharge, self-discharge characterization, self-discharge modeling, supercapacitor.

\section{INTRODUCTION}

$\mathbf{O}$ VER years, electrochemical capacitors have acquired many names coined by manufacturers including supercapacitors, ultracapacitors, double-layer capacitors, etc.

Electrochemical capacitors are used more and more for storing electrical energy in different fields, for example, in communications, electric and hybrid vehicles, etc. They offer interesting electrical characteristics and high-lifetime cycling compared to that of batteries [1], [2].

An electrochemical capacitor stores energy by two processes. The main process is by the separation of positive and negative charges at the interfaces between the electrode and the electrolyte. This phenomenon is called double-layer capacitance. The second technique stores charge by reversible Faradic redox processes (electron-transfer reactions between the electrodes and the electrolyte) [3], [4]. These components can lose their stored energy fast compared to chemical cells, particularly at high temperatures and voltages [5]. Since self-discharge is an

Manuscript received January 22, 2008; revised May 15, 2008; accepted September 16, 2008. First published December 16, 2008; current version published February 6, 2009. Recommended for publication by Associate Editor A. Rufer.

Y. Diab was with the Laboratoire Ampère, Unité Mixte de Recherche, Centre National de la Recherche Scientifique (UMR-CNRS), Université Lyon 1, 69622 Villeurbanne, France. He is now with the University of Damascus, Damascus, Syria.

P. Venet and G. Rojat are with the Laboratoire Ampère, Unité Mixte de Recherche, Centre National de la Recherche Scientifique (UMR-CNRS), Université Lyon 1, 69622 Villeurbanne, France.

H. Gualous is with the SET-Franche-Comté (FC) Laboratory, University of Technology of Belfort-Montbéliard, Université de Franche-Comté (UTBMUFC), 90010 Belfort, France.

Digital Object Identifier 10.1109/TPEL.2008.2007116
TABLE I

STUdied ElECTROCHEMICAL CAPACITORS PARAMETERS AS GIVEN IN THE MANUFACTURER'S DATASHEET

\begin{tabular}{|c|c|c|c|c|c|c|}
\hline Manufacturer & \multicolumn{4}{|c|}{$\overline{\mathbf{A}}$} & B & $\mathrm{C}$ \\
\hline Component & 1 & 2 & 3 & $\overline{4}$ & - & - \\
\hline Rated Capacitance $\mathrm{C}_{\mathrm{R}}(\mathrm{kF})$ & 2.6 & 0.45 & 0.35 & 2.6 & 2.6 & 3.6 \\
\hline Rated voltage $U_{R}(V)$ & 2.5 & 2.5 & 2.5 & 2.7 & 2.7 & 2.5 \\
\hline Rated current (A) & 600 & 180 & 30 & 600 & - & - \\
\hline Leakage current $I_{\mathrm{lem}}(\mathbf{m A})$ & $\begin{array}{c}5 \\
12 \mathrm{~h}\end{array}$ & $\begin{array}{c}3 \\
72 \mathrm{~h}\end{array}$ & $\begin{array}{c}1 \\
72 \mathrm{~h}\end{array}$ & $\begin{array}{c}5 \\
72 \mathrm{~h}\end{array}$ & - & - \\
\hline
\end{tabular}

important indicator to quantify the performances of an electrochemical capacitor (aging, energetic efficiency, etc.), we are interested in studying this phenomenon in detail under different constraints such as thermal and potential. This paper illustrates the behavior of self-discharge in symmetric electrochemical capacitors, which are carbon-based with organic electrolyte. The self-discharge is interpreted and modeled by its mechanisms using various approaches, one of which is new. In order to generalize our experimental study, we have examined the self-discharge of commercial electrochemical capacitors, which have different capacities and rated voltages, and are produced by different manufacturers. The components studied in this paper will be called A, B, and C, as shown in Table I. Components $\mathrm{A}_{1}, \mathrm{~A}_{2}$, and $\mathrm{A}_{3}$ are fabricated using the same technology.

\section{CHARACTERIZATION AND MODELING OF THE ELECTROCHEMICAL CAPACITOR}

The electrochemical capacitor can be presented by various equivalent circuits based on physical phenomena. However, in power electronics, we often employ the equivalent circuit shown in Fig. 1. This circuit models an electrochemical capacitor by two time constants. The $R_{1} C_{1}$ cell is the main branch that determines energy evolution during charge and discharge cycles in power electronics applications (charge and discharge in a few seconds). It is called an immediate branch. The $R_{2} C_{2}$ cell is the delayed branch; it completes the first cell in long time range and describes the internal energy distribution at the end of the charge (or discharge).

The immediate parameters can be identified by passing a high-charge current, while delayed parameters can be identified by measuring the open-circuit voltage [6].

The differential capacitance $C_{1}(u)$ is presented by two capacitances: a constant capacitance $C_{0}$ and a linear voltagedependent capacitance $k$

$$
C_{1}(u)=C_{0}+k u \text {. }
$$




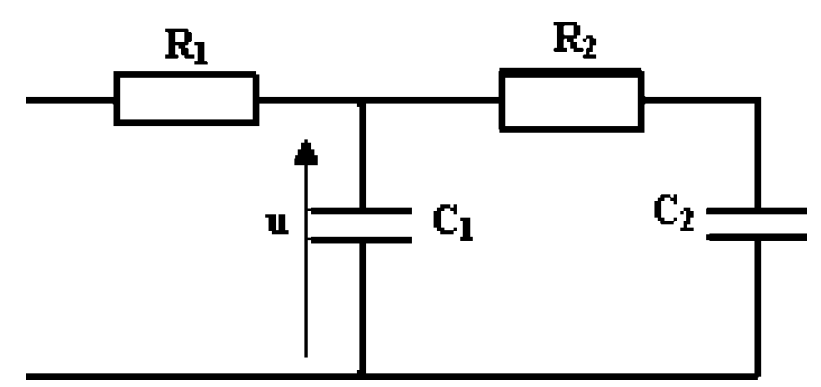

Fig. 1. Two-branch model of an electrochemical capacitor.

TABLE II

EQuivalent Circuit PaRAMETERS OF CAPACITOR $\mathrm{A}_{1}$

\begin{tabular}{|c|c|c|c|c|c|}
\hline Parameter & $\mathbf{R}_{1}$ & $\mathbf{R}_{\mathbf{2}}$ & $\mathbf{C}_{\mathbf{0}}$ & $\mathbf{k}$ & $\mathbf{C}_{\mathbf{2}}$ \\
\hline Unit & $\mathrm{m} \Omega$ & $\Omega$ & $\mathrm{kF}$ & $\mathrm{kF} / \mathrm{V}$ & $\mathrm{kF}$ \\
\hline Value & 0.46 & 1.98 & 1.78 & 0.47 & 0.18 \\
\hline
\end{tabular}

The resistance $R_{1}$ can be determined by the ratio of voltage drop at the beginning of charging to current. The constant $C_{0}$ in (1) can be determined from the definition of differential capacity $I / d u(0) / d t$, determined near to initial instant of charging. The slope $k$ can be identified by the evolution of voltage $\Delta U_{t}$ and $I \Delta t_{t}$ charge of the capacitor stored during charging as follows [6]:

$$
k=\frac{2\left(I \Delta t_{t}-C_{0} \Delta U_{t}\right)}{\Delta U_{t}^{2}}
$$

After stopping electric supply at voltage $U_{a}$, the relaxing phenomena is observed. At some later time $\Delta t$, the capacitor voltage decreases by $\Delta U$. The resistance $R_{2}$ can be determined by the following equation [6]:

$$
R_{2}=\frac{U_{a}-\Delta U / 2}{C_{1}} \frac{\Delta t}{\Delta U}
$$

The capacity $C_{2}$ can be calculated after a period of several minutes. The conservation charge equation allows establishing the expression of $C_{2}$ depending on $Q_{0}$ (storing charge in capacitor) and $U_{b}$ (voltage at the end of relaxing phenomena). Thus, we obtain the following relationship [6]:

$$
C_{2}=\frac{Q_{0}}{U_{b}}-\left(C_{0}+\frac{k}{2} U_{b}\right) .
$$

Table II shows an example of the equivalent circuit parameters determined as mentioned before, and by using a charging current of about $60 \%$ of the rated value.

\section{Self-Discharge Measurements}

In order to limit the relaxing phenomena effect on the selfdischarge measurement, the capacitor is charged with a constant voltage supply for $1 \mathrm{~h}$. After $1 \mathrm{~h}$, all the components of the capacitor are approximately charged to the same voltage, assuming that the relaxing phenomena have time constants of less than $1 \mathrm{~h}$. Consequently, when the charging current is stopped, the

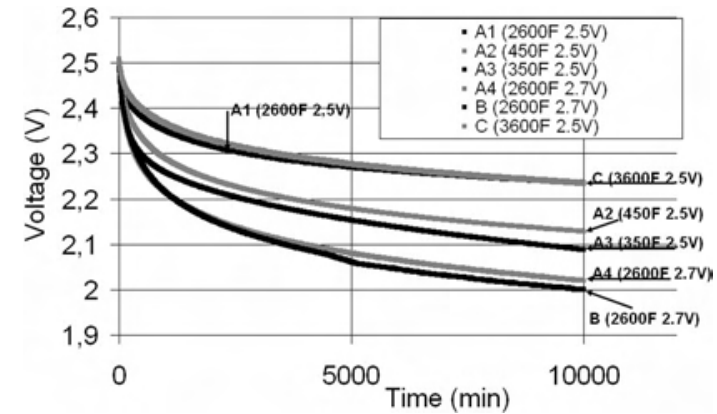

Fig. 2. Self-discharge of the capacitor.

decrease in voltage across the capacitor follows only the effect of self-discharge [5].

It has been found that a gradual decrease in voltage across the capacitor occurs in open circuit, principally within the first hours due to Faradic reactions at double layer. We measured the open-circuit voltage of the capacitor by means of a USB voltage module with 32 channels (with an internal resistance of $10 \mathrm{M} \Omega$ ) programmed using LabView. To measure the selfdischarge, the following procedures are carried out: first, by charging capacitors (as described before); second, by measuring the open-circuit voltage of capacitors over a period of seven days; and finally, discharging and short-circuiting them during two days.

Fig. 2 shows the self-discharge of the aforementioned capacitors at an ambient temperature of $25^{\circ} \mathrm{C}$ and for an initial voltage of $2.5 \mathrm{~V}$. It illustrates that the self-discharge rates of different components are different. It is noticed that components $\mathrm{A}_{4}$ and $\mathrm{B}$ have the highest self-discharge rates, whereas components $\mathrm{A}_{1}$ and $\mathrm{C}$ have the smallest rate.

\section{SELF-Discharge MechanismS}

An electrochemical capacitor in a charged state is in a state of high positive free energy relative to that in a discharged state. There is a virtual driving force that tends to discharge it. If a process is available, then self-discharge can take place [7]. It has been noted that the self-discharge slows down after several hours, as shown in Fig. 2, because some mechanisms diminish. Thus, the electrochemical capacitor returns gradually to the stable state.

Three distinguishable kinds of self-discharge mechanisms can operate [9].

Self-discharge at cell overvoltage: At the electrodes polarized to overvoltage, decomposition of electrolyte starts producing gases [7].

Self-discharge due to Faradic impurity reactions: Some ionic species in the electrolyte can undergo Faradic redox reactions, building up a concentration of an ionic species near the carbon surfaces [5].

Leakage current: There is a leakage of charge between one electrode interface and another through a load in improperly sealed bipolar cell designs [8]. 


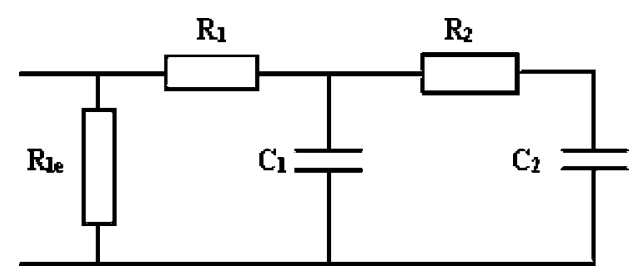

Fig. 3. Equivalent circuit of an electrochemical capacitor taking into account the leakage current.

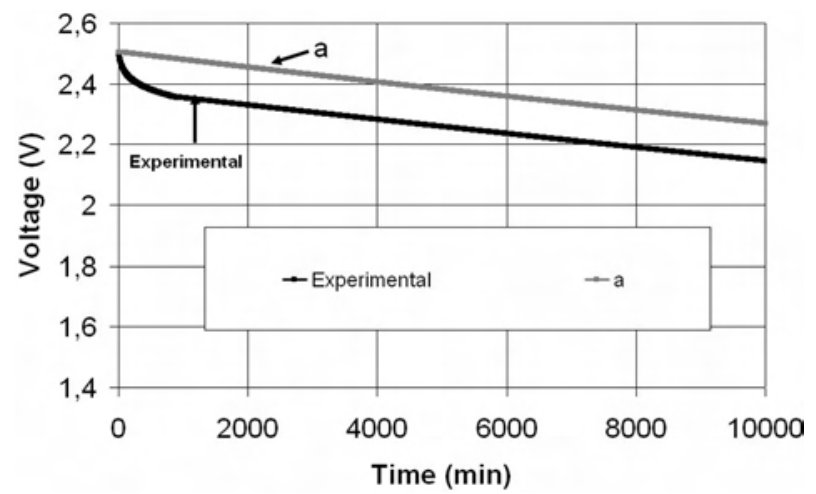

Fig. 4. Comparison of leakage current simulation with experimental results; "a" refers to simulation of the circuit shown in Fig. 3.

\section{SelF-Discharge Modeling}

\section{A. Leakage Current Modeling}

To take into account in the modeling of the electrochemical capacitor the self-discharge process due to leakage charges, we added a resistance $R_{\mathrm{le}}$ in parallel in an equivalent circuit of the capacitor (see Fig. 3). In this case, the voltage across the capacitor decreases as an exponential function of time as follows:

$$
u(t)=U_{0} \exp \left(-\frac{t}{\tau_{\mathrm{le}}}\right)
$$

where $U_{0}$ is the initial voltage and $\tau_{\text {le }}$ is the time constant of leakage current. The time constant is determined experimentally, and the decline of open-circuit voltage is approximated by an exponential function. The Faradic leakage resistance $R_{\mathrm{le}}$ is calculated as follows:

$$
R_{\mathrm{le}}=\frac{\tau_{\mathrm{le}}}{C_{1}(u)}
$$

where $C_{1}(u)$ is the equivalent capacity of the capacitor. The equivalent capacity of the electrochemical capacitor can be represented only by $C_{1}(u)$ because the relaxing effect is relatively low here.

The circuit shown in Fig. 3 with the parameters of capacitor $\mathrm{A}_{1}$ was implanted in Simplorer software. The simulation results (Fig. 4) show an important error (4\% mean relative error) compared with the experimental results because we modeled the self-discharge only by a simple resistance, while it must take into account the self-discharge due to a diffusion-controlled Faradic process as well. The same results can be obtained for other capacitors, but with difference more or less according to the
TABLE III

NormaLized LEAKage Resistance of MANUfacturer A

\begin{tabular}{|c|c|c|c|c|}
\hline Manufacturer & \multicolumn{5}{|c|}{ A } \\
\hline Component & 1 & 2 & 3 & 4 \\
\hline Manufacturer leakage resistance $\left(\mathbf{R}_{\text {lem }}\right)(\mathbf{k} \boldsymbol{\Omega})$ & 0.50 & 0.83 & 2.5 & 0.54 \\
\hline $\begin{array}{c}\text { Capacitance } \\
\mathbf{C}_{\mathbf{R}}(\mathbf{k F})\end{array}$ & 2.6 & 0.45 & 0.35 & 2.6 \\
\hline $\mathbf{R}_{\mathrm{le}}(\mathbf{k} \boldsymbol{\Omega})$ & 1.34 & 4.99 & 8.0 & 0.73 \\
\hline $\mathbf{R}_{\mathrm{le}} / \mathbf{R}_{\mathrm{len}} \%$ & 269 & 599 & 321 & 135 \\
\hline $\mathbf{R}_{\mathrm{le}} / \mathbf{C}_{\mathbf{R}}(\boldsymbol{\Omega} / \mathbf{F})$ & 0.52 & 11.1 & 23.0 & 0.28 \\
\hline
\end{tabular}

magnitude of self-discharge with diffusion-controlled Faradic process.

In order to normalize the experimental results obtained in our study and compare the self-discharge parameters for different components, we calculated a manufacturer leakage resistance $\left(R_{\mathrm{lem}}\right)$ according to the leakage current $\left(I_{\mathrm{lem}}\right)$ and the operating voltage $\left(U_{R}\right)$ given in the manufacturer's datasheet

$$
R_{\mathrm{lem}}=\frac{U_{R}}{I_{\mathrm{lem}}} .
$$

The normalized leakage resistances for manufacturer A are shown in Table III. We could not normalize the results for manufacturers $\mathrm{B}$ and $\mathrm{C}$ because they did not specify a value of leakage current in the datasheet. Table III illustrates that leakage resistance increases with a decrease of capacitance because membrane surface and quantity of impurities are lower.

\section{B. Diffusion-Controlled Faradic Process Modeling}

During the charging of an electrochemical capacitor up to a threshold voltage, accumulation of an excess ionic concentration can take place near the carbon-electrolyte interface. After disconnecting the capacitor from the charging circuit, the charge stays in place (forming the double-layer capacitance), but part of the charge undergoes self-discharge due to the presence of impurities. Some of the ions will diffuse into the electrolyte and others will diffuse to the carbon surface where they will reduce the number of excess charges in the carbon. The decrease in the open-circuit voltage of the capacitor can be approximately described by the following equation [5]:

$$
u(t) \approx U_{0}-m \sqrt{t}
$$

where $m$ is the diffusion parameter that can be calculated by

$$
m=\frac{C_{R 0} q \sqrt{D}}{C_{12} \sqrt{\pi}}
$$

where $D$ is the diffusion coefficient of the ions in the electrolyte, $C_{12}$ is the series combination of the capacitances at the two interfaces of the capacitor per unit area of one of the interfaces, $C_{R_{0}}$ is the initial ionic species concentration at the electrodeelectrolyte interfaces, and $q$ is the charge carried to the carbon surface by each ion [5]. These parameters can be identified by a physicochemical analysis of capacitor electrolyte.

For example, for $\mathrm{A}_{1}, m=7 \mathrm{mV} / \mathrm{s}^{1 / 2}$.

Equation (8) can describe the self-discharge of a Faradic redox process during $8 \mathrm{~h}$ or so, where the leakage current is low 


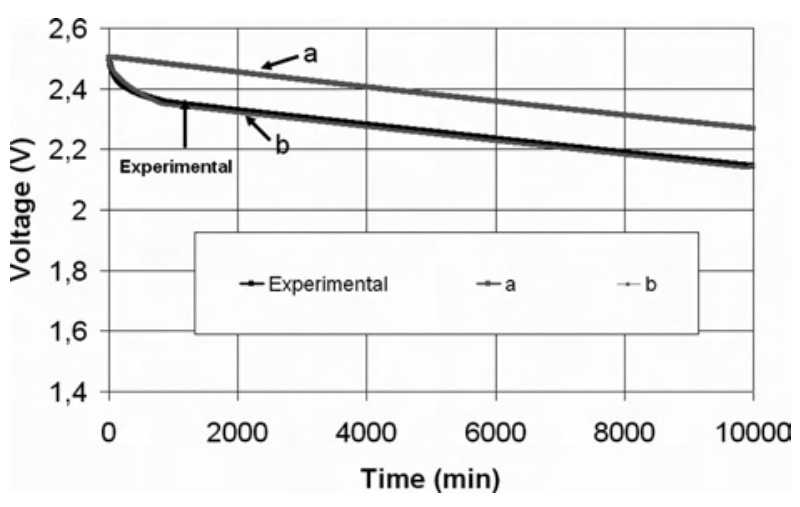

Fig. 5. Comparison of the simulation with the experimental results ("b" refers to the modeling as described before).

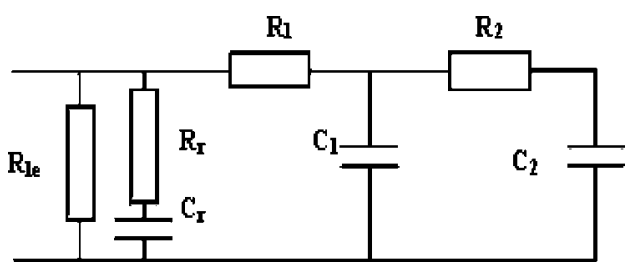

Fig. 6. Equivalent circuit of the electrochemical capacitor taking into account the self-discharge.

and can be considered negligible [10]. The self-discharge is the superimposition of both the mechanisms described in (2) and (5). Hence, capacitor self-discharge can be modeled by combining both the equations. As shown in Fig. 5, there is a low tolerance $(0.3 \%$ mean relative error) between the experimental results and simulation. Nevertheless, this model requires some physical parameters that are difficult to determine.

\section{Experimental Approach}

We suggest simplifying the modeling of the self-discharge of the Faradic process reactions. The diffusion of charge into the carbon surface is approximately represented by an equivalent circuit. This allows us to represent the entire self-discharge in the electrical equivalent circuit, and especially to quantify the selfdischarge due to diffusion-controlled Faradic redox reactions (see Fig. 6). This circuit demonstrates that part of the charge stored immediately in capacitance $C_{1}$ will be redistributed into capacitances $C_{2}$ and $C_{r}$. $C_{2}$ has a negligible effect. The redistribution phenomenon effect is relatively low because the capacitor is charged during an hour. When the supply current is stopped, the charge $Q_{0}$ stored in $C_{1}$ will be redistributed to $C_{r}$ as $C_{r}$ has an almost zero voltage. At the end of the diffusion-controlled Faradic process, both capacitances $C_{1}$ and $C_{r}$ will have the same voltage $U_{r}$, with total charge $Q_{r}$. The capacitance $C_{r}$ can be determined by using the charge balance

$$
Q_{r}=Q_{0}
$$

where

$$
\begin{aligned}
& Q_{r}=U_{r}\left(C_{1}(u)+C_{r}\right) \\
& Q_{0}=U_{0} C_{1}(u) .
\end{aligned}
$$

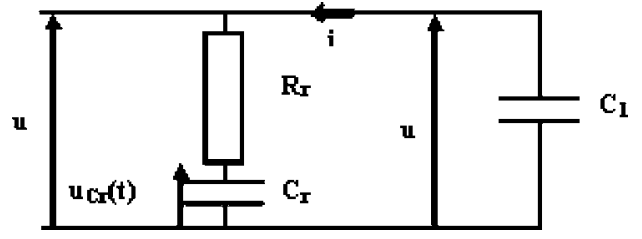

Fig. 7. Equivalent circuit of the capacitor during self-discharge with diffusioncontrolled.

As a result

$$
C_{r}=\frac{C_{1}(u)\left(U_{0}-U_{r}\right)}{U_{r}} .
$$

The circuit schematized in Fig. 6 can be reduced to that shown in Fig. 7 during self-discharge with diffusion-controlled Faradic process.

From this figure, we can write the following equations:

$$
\begin{aligned}
& u(t)=i(t) R_{r}+u_{C_{r}}(t) \\
& i(t)=C_{r} \frac{d u_{C_{r}}(t)}{d t}=-C_{1} \frac{d u(t)}{d t} .
\end{aligned}
$$

Thus, we can deduce the time evolution of capacitor voltage during self-discharge with diffusion-controlled Faradic process

$$
C_{1} R_{r} \frac{d^{2} u(t)}{d t^{2}}+\frac{C_{1}+C_{r}}{C_{r}} \frac{d u(t)}{d t}=0 .
$$

The solution of this equation with presented initial conditions can be estimated by

$$
u(t)=U_{0} \exp \left(-\frac{t}{\tau_{r}}\right)
$$

where $\tau_{r}$ is the constant time of self-discharge due to diffusioncontrolled, which can be calculated by the following equation:

$$
\tau_{r}=\frac{C_{1} C_{r} R_{r}}{C_{1}+C_{r}}
$$

Assuming that the capacitance $C_{1} \gg C_{r}$, the time constant can be reduced as follows:

$$
\tau_{r}=C_{r} R_{r} .
$$

The time constant of the exponential described in (17) was determined experimentally by fitting (with the software of nonlinear least-squares fit) the difference between the leakage exponential current and the experimental result during the first hours. The resistance $R_{r}$ ascribed to the evolution of Faradic reactions at the electrode-electrolyte interfaces can be calculated by

$$
R_{r}=\frac{\tau_{r}}{C_{r}} .
$$

There is a slight difference between the circuit simulation (shown in Fig. 6) and the experimental results (1.2\% mean relative error) (see Fig. 8). This difference is slightly higher than that found in the previous section. In spite of this, the experimental results demonstrate that the self-discharge can be entirely represented by an equivalent circuit with low error. This circuit is more advantageous than the model described in the previous section because it is easy to establish, and allows estimating the magnitude of the electrochemical storage of energy in an electrical double-layer capacitor. 


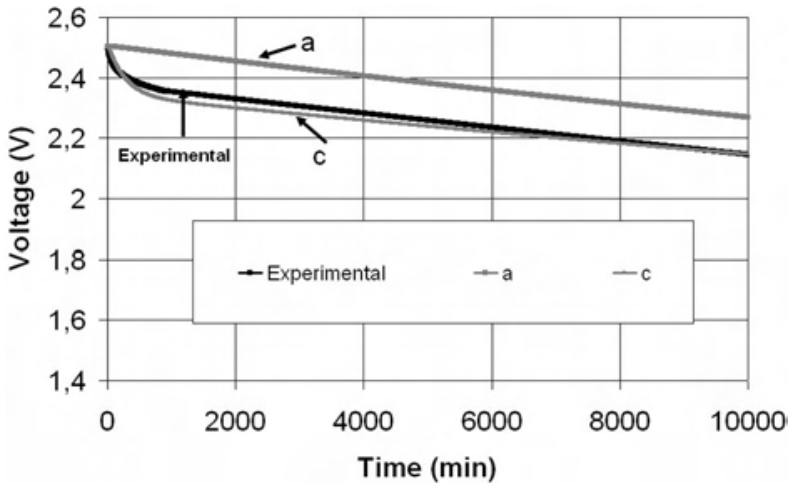

Fig. 8. Comparison of the simulation results with the model depicted in Fig. 6 referred by "c."

TABLE IV

SELF-DischaRge PARAMETERS OF THE STUDIED ELECTROCHEMICAL CAPACITORS

\begin{tabular}{|c|c|c|c|c|}
\hline Manufacture & \multicolumn{4}{|c|}{$\mathbf{A}$} \\
\hline Component & 1 & 2 & 3 & 4 \\
\hline $\begin{array}{c}\text { Capacitance } \\
\mathbf{C}_{\mathbf{R}}(\mathrm{kF})\end{array}$ & 2.6 & 0.45 & 0.35 & 2.6 \\
\hline $\mathbf{R}_{\mathbf{r}}(\mathbf{\Omega})$ & 58.1 & 291 & 384 & 45.2 \\
\hline $\mathbf{C}_{\mathbf{r}}(\mathbf{F})$ & 201 & 47.4 & 38.8 & 367 \\
\hline $\mathbf{C}_{\mathbf{r}} / \mathbf{C}_{\mathbf{R}} \%$ & 8 & 11 & 11 & 14 \\
\hline
\end{tabular}

Table IV shows the self-discharge parameters normalized to those given in the manufacturer's datasheet. We remark that the capacitance $C_{r}$ rises with an increase in capacitance of the capacitor because the redox increases with an increase in electrode-electrolyte interfaces. Component $A_{1}$ has a relative capacitance $C_{r} / C_{R}$ lower than that of $\mathrm{A}_{2}$ because the concentration of impurities per unit area of electrode-electrolyte interface is low at high capacitances [7]. Component $\mathrm{A}_{4}$ has the highest capacitance $C_{r}$ and the lowest resistances, which signifies that this component dissipates an important stored energy compared to that of others. This is because of using a technology for component $\mathrm{A}_{4}$ different from components $\mathrm{A}_{1}, \mathrm{~A}_{2}$, and $\mathrm{A}_{3}$.

\section{EFFect of Initial Voltage on Self-Discharge Rates}

The self-discharges of capacitor $A_{1}$ for voltages of 0.5, 1.0, $1.5,2.0$, and $2.5 \mathrm{~V}$ and at a temperature of $25^{\circ} \mathrm{C}$ are illustrated in Fig. 9. The self-discharge rate is quite rapid for high voltages $(1.5,2.0,2.5 \mathrm{~V})$ and slow for the low voltages $(0.5,1.0 \mathrm{~V})$. As a result, when the initial voltage reduces, the self-discharge rate diminishes as well.

An increase in the voltage across the electrochemical capacitor accelerates the process leading to excess ionic concentrations $C_{R_{0}}$ near the electrodes of the electrochemical capacitor [5]. Consequently, an increase in the diffusion parameter $m$ can take place, causing a fast decline in the voltage [see (8)]. This occurs only when the voltage across the supercapacitor becomes higher than the threshold voltage [5].

In Figs. 10-12, the self-discharge parameters are determined as a function of the initial voltage at $25^{\circ} \mathrm{C}$. The experimental results show that the capacitance $C_{r}$ increases with an increase of

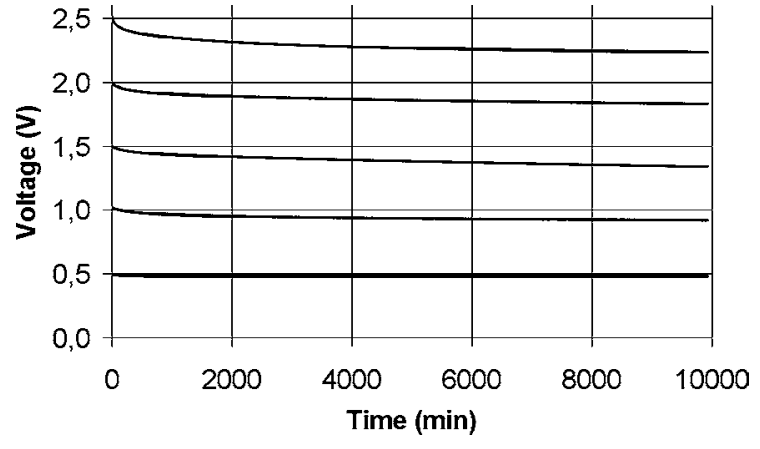

Fig. 9. Self-discharge of capacitor $A_{1}$ at various initial voltages.

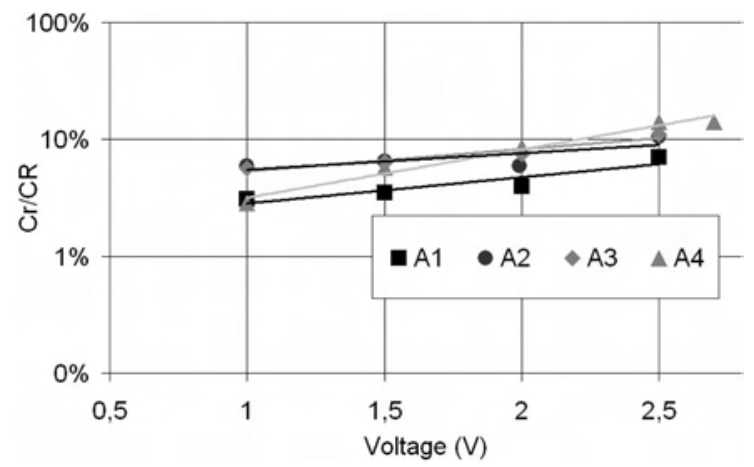

Fig. 10. Capacitance $C_{r}$ normalized to $C_{R}$ versus initial voltage.

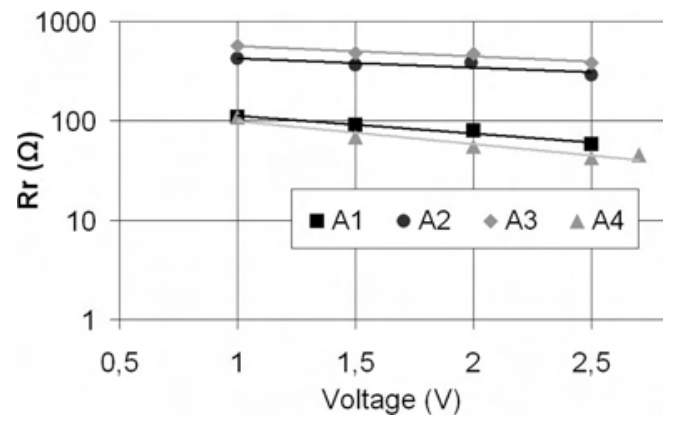

Fig. 11. Resistance $R_{r}$ versus initial voltage.

the initial voltage as a result of an increase in the ionic concentration while the resistances $R_{r}$ and $R_{\mathrm{le}}$ are slightly decreased.

From these figures, we can note that capacitor $\mathrm{A}_{4}$ has the highest capacitance $C_{r}$ and the lowest resistance $R_{\mathrm{le}}$ compared to that of the other capacitors at high initial voltages. It means that this component has the most important self-discharge rates.

\section{EFFect of Temperature on Self-Discharge Rates}

The electrochemical capacitors can operate in a temperature range as wide as from $-35{ }^{\circ} \mathrm{C}$ to $65^{\circ} \mathrm{C}$. Fig. 13 shows the capacitance $C_{1}(u)$ of capacitor $\mathrm{A}_{1}$ at different temperatures normalized to that of $25^{\circ} \mathrm{C}$ and at full charge $(2.5 \mathrm{~V})$. It demonstrates that the capacitance of capacitor is not dependent on temperature. As a result, the variation of capacitance $C_{1}(u)$ as a function of temperature is neglected in the determination of self-discharge parameters. 


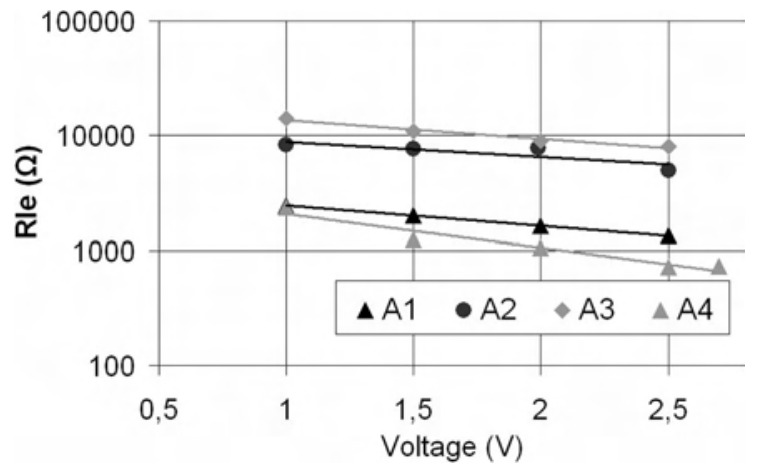

Fig. 12. Resistance $R_{\text {le }}$ versus initial voltage.

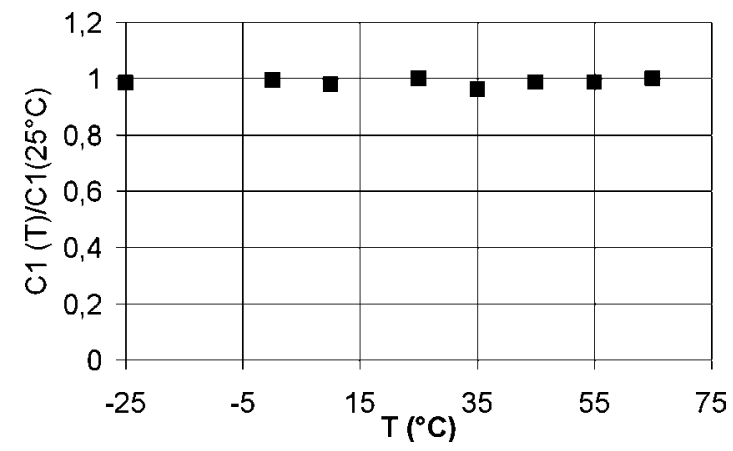

Fig. 13. Capacitance of capacitor $A_{1}$ as a function of temperature.

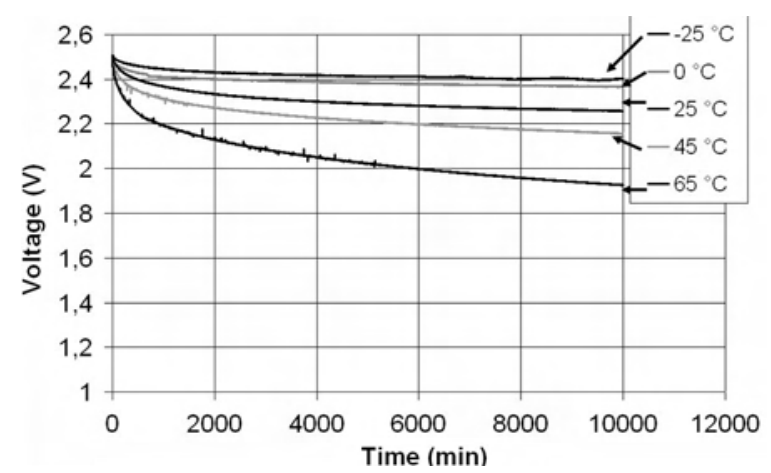

Fig. 14. Self-discharge of capacitor $\mathrm{A}_{1}$ at different temperatures.

Fig. 14 shows the self-discharge of component $\mathrm{A}_{1}$ measured at $-25^{\circ} \mathrm{C}, 0{ }^{\circ} \mathrm{C}, 25^{\circ} \mathrm{C}, 45^{\circ} \mathrm{C}$, and $65^{\circ} \mathrm{C}$ for an initial voltage of $2.5 \mathrm{~V}$. The self-discharge rates accelerate strongly with an increase in temperature. Since self-discharge rates are dependent on the rates of ionic transport, it is to be expected that selfdischarge will become more rapid as the temperature of the capacitor is increased [5].

The self-discharge parameters determined at full charge (2.5 V for $\mathrm{A}_{1}, \mathrm{~A}_{2}$, and $\mathrm{A}_{3}$, and $2.7 \mathrm{~V}$ for $\mathrm{A}_{4}$ ) for different temperatures are shown in Figs. 15-17. The self-discharge parameters are highly influenced by the temperature, especially by positive temperatures. Consequently, the resistances $R_{\mathrm{le}}$ and $R_{r}$ decrease when the temperature increases while the capacitance $C_{r}$ increases (see Figs. 15-17). Finally, we also notice that the self-discharge of component $\mathrm{A}_{4}$ is more influenced by the increase in temperature than that of others.

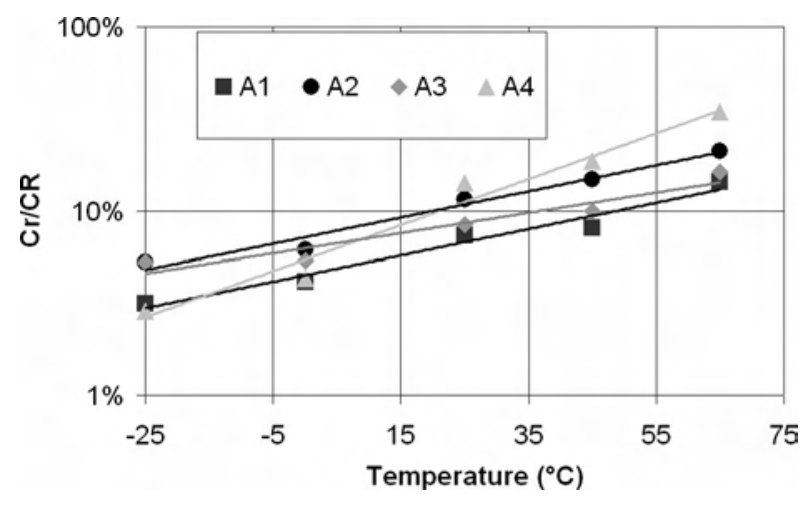

Fig. 15. Capacitance $C_{r}$ normalized to $C_{R}$ versus temperature.

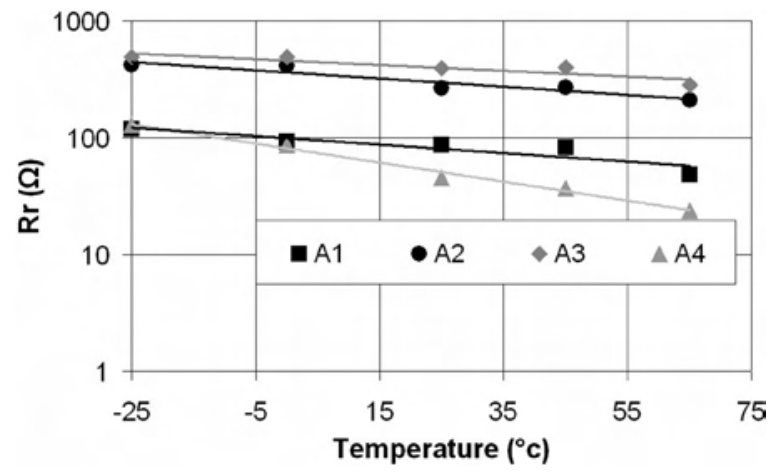

Fig. 16. Resistance $R_{r}$ versus temperature.

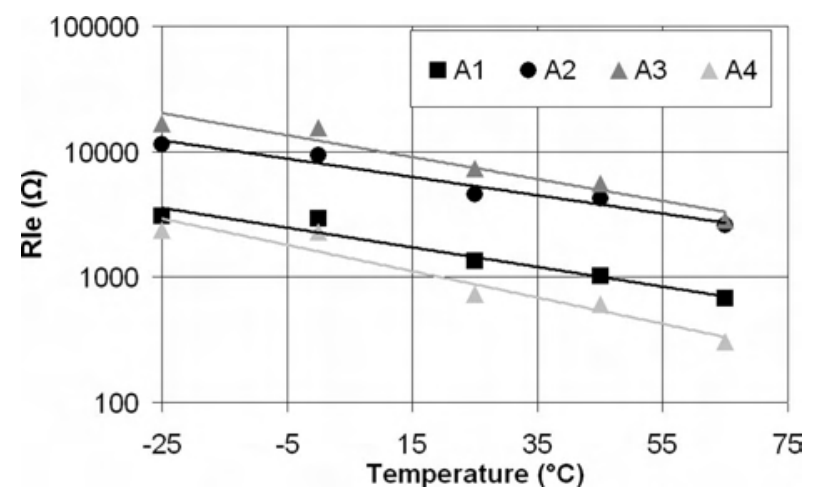

Fig. 17. Resistance $R_{\text {le }}$ versus temperature.

Consequently, there are principally two time constants of selfdischarge: one for diffusion-controlled Faradic process and the other for leakage current. The resistance $R_{r}$ determined in our study consistently appears lower than that given by the manufacturer, whereas the resistance $R_{\mathrm{le}}$ is higher because measurement periods are different (here, it is about seven days). The last resistance can vary as a function of the time measurement, as we explained previously, because the capacitor returns to the stable state with time. As a result, the leakage current slows down gradually and the leakage resistance increases.

Finally, we remark that the variation of self-discharge parameters as a function of initial voltage and temperature can be represented by an exponential function. 


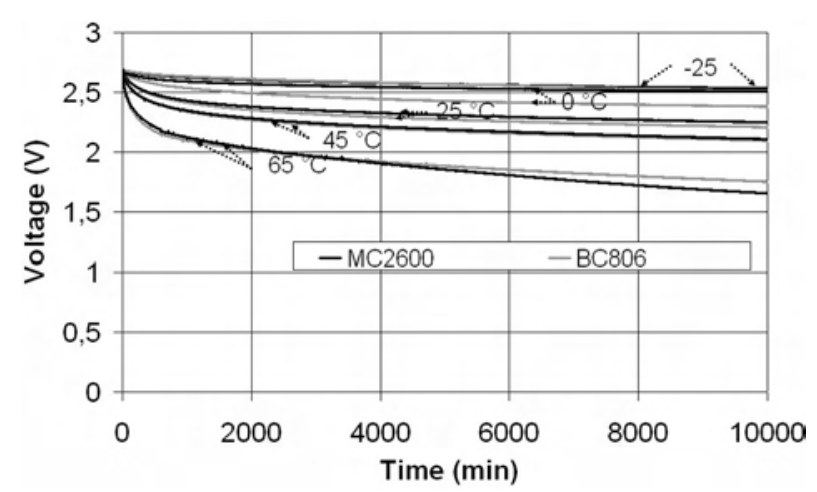

Fig. 18. Self-discharge of components $\mathrm{A}_{4}$ and $\mathrm{B}$ measured with initial voltage of $2.7 \mathrm{~V}$.

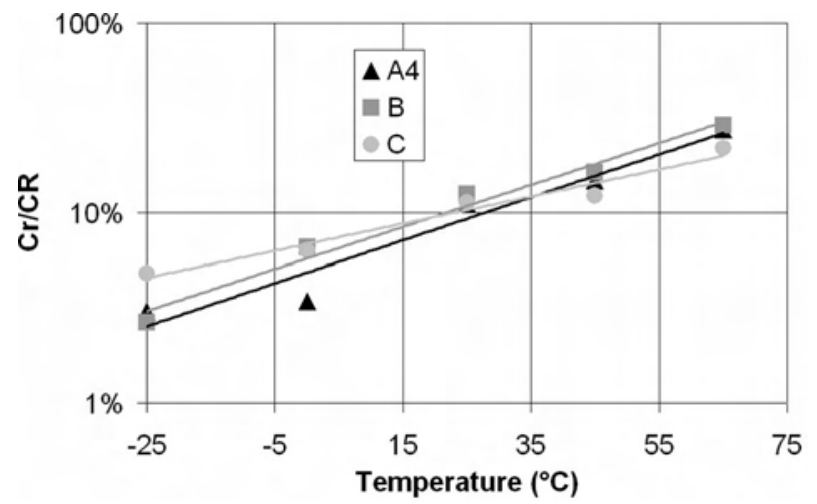

Fig. 19. Capacitance $C_{r}$ normalized to $C_{R}$ versus temperature for components $\mathrm{A}_{4}, \mathrm{~B}$, and $\mathrm{C}$.

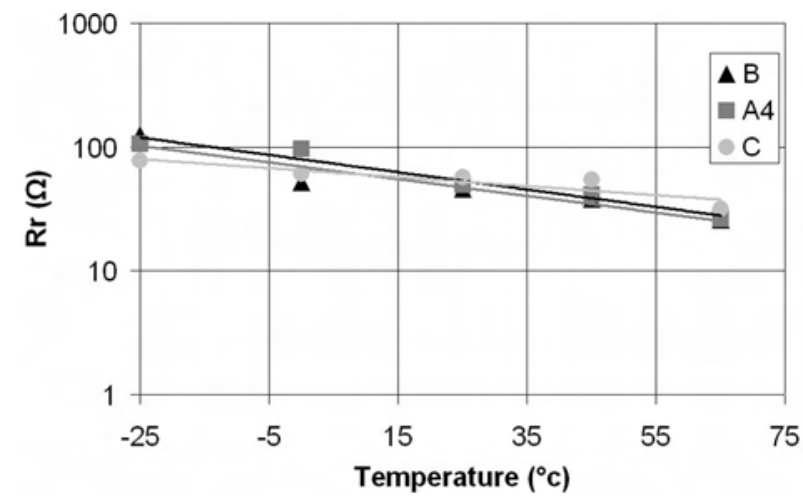

Fig. 20. Resistance $R_{r}$ versus temperature for components $\mathrm{A}_{4}, \mathrm{~B}$, and $\mathrm{C}$.

\section{ELECTROCHEMICAL CAPACITOR FOR DIFFERENT MANUFACTURERS}

For the same rated voltage $(2.7 \mathrm{~V})$ and capacitance $(2600 \mathrm{~F})$ but produced by different manufacturers, we will compare both the components $\mathrm{A}_{4}$ and B. Fig. 18 shows the self-discharge of both the components at different temperatures. We observe that there is a small tolerance in the self-discharge parameters for both the components (see Figs. 19-21).

We observe from Figs. 19-21 that component $\mathrm{C}$ has very low self-discharge rates, and they are slightly influenced by the variation of the initial voltage and temperature.

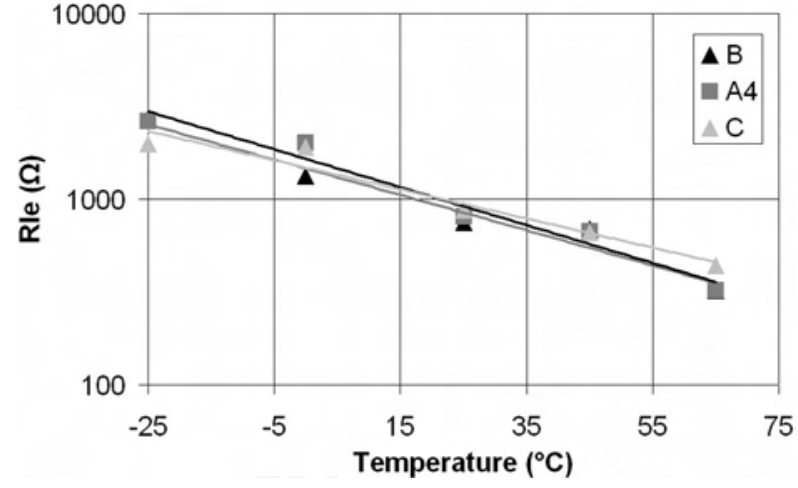

Fig. 21. Resistance $R_{\text {le }}$ versus temperature for components $\mathrm{A}_{4}, \mathrm{~B}$, and C.

\section{Summary AND PERSPECTIVES}

The total capacitance of an electrochemical capacitor is the sum of both the capacitances. The first is the useful capacitance due to the double-layer capacitance. The second is the useless capacitance due to the redox reaction at the electrode-electrolyte interfaces.

An important loss of the stored energy in carbon-based electrochemical capacitors with organic electrolytes occurs, especially within the first hours. This loss will augment at high temperatures and voltages as there is a strong dependence of self-discharge parameters on the temperature and the initial voltage. It can be seen that the modeling of entire self-discharge by an equivalent circuit presents satisfactory simulation results, and also allows us to evaluate the self-discharge and the losses in stored energy of different electrochemical capacitors. The equivalent circuit of self-discharge can be easily integrated into simulation software (Simplorer, Matlab, etc.). The electrochemical capacitors modules can be precisely optimized for a given application with the help of the established model.

There is a relationship between the self-discharge and aging behavior. Hence, we envisage nearly measuring and analyzing the self-discharge according to the aging behavior.

\section{REFERENCES}

[1] L. Gao, R. A. Dougal, and S. Liu, "Power enhancement of an actively controlled battery/ultracapacitor hybrid," IEEE Trans. Power Electron., vol. 20, no. 1, pp. 236-243, Jan. 2005.

[2] S.-M. Kim and S.-K. Sul, "Control of rubber tyred gantry crane with energy storage based on supercapacitor bank," IEEE Trans. Power Electron., vol. 21, no. 5, pp. 1420-1427, Sep. 2006.

[3] M. Williams and J. L. Davis, "Mixedvalence complex electrodes for a rechargeable electrical energy storage device," U.S. Patent 5383 089, Jan. 17, 1995.

[4] K. H. An, K. K. Jeon, J. K. Heo, S. C. Lim, D. J. Bae, and Y. H. Lee, "Highcapacitance supercapacitor using a nanocomposite electrode of singlewalled carbon nanotube and polypyrrole," J. Electrochem. Soc., vol. 149, no. 8, pp. A1058-A1062, 2002.

[5] B. W. Ricketts and C. Ton-That, "Self-discharge of carbon-based supercapacitors with organic electrolytes," J. Power Sources, vol. 89, no. 1, pp. 64-69, 2000.

[6] L. Zubieta and R. Bonert, "Characterization of double-layer capacitors for power electronics," IEEE Trans., vol. 36, no. 1, pp. 199-205, Jan./Feb. 2000.

[7] B. E. Conway, Electrochemical Supercapacitors: Scientific Fundamentals and Technological Applications. Boston, MA/New York: Kluwer/Plenum, 1999, pp. 557-595. 
[8] J. J. Niu, B. E. Conway, and W. G. Pell, "Comparative studies of selfdischarge by potential decay and float-current measurements at $C$ doublelayer capacitor and battery electrodes," J. Power Sources, vol. 135, no. 1/2, pp. 332-343, 2004.

[9] B. E. Conway, W. G. Pell, and T.-C. Liu, "Diagnostic analyses for mechanisms of self-discharge of electrochemical capacitors and batteries," $J$. Power Sources, vol. ss65, pp. 53-59, 1997.

[10] P. Venet, Z. Ding, A. G. Rojat, and H. Gualous, "Modelling of the supercapacitors during self-discharge," EPE J., vol. 17, no. 1, pp. 6-10, Mar. 2007.

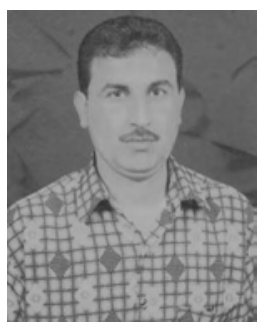

Yasser Diab was born in Damascus, Syria, in 1975. $\mathrm{He}$ received the $\mathrm{Ph} . \mathrm{D}$. degree in electrical engineering from the Université Lyon 1, Villeurbanne, France, in 2008.

Since 2001, he has been a Researcher and a Lecturer Assistant at the University of Damascus, Damascus. His current research interests include energy storage systems and power electronics.

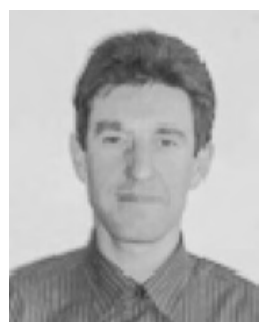

Pascal Venet was born in Aix-Les-Bains, France, on March 16, 1965. He received the Ph.D. degree in electrical engineering from the Université Lyon 1, Villeurbanne, France, in 1993.

Since 1995, he has been an Assistant Professor at the Université Lyon 1, where he conducts his research activities in the Laboratoire Ampère. His current research interests include static converters, fault diagnostics, and aging of components such as electrolytic capacitors, supercapacitors, and batteries.

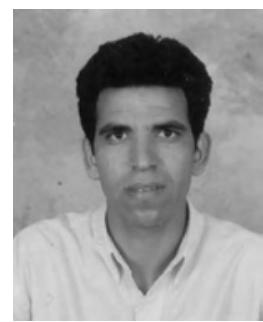

Hamid Gualous was born in Morocco in 1967. He received the $\mathrm{Ph} . \mathrm{D}$. degree in electronics from the University Paris XI, Orsay, France, in 1994.

Since 1996, he has been an Assistant Professor at the Université de Franche-Comté, Belfort, France. His current research interests include energy storage devices (supercapacitor and batteries), hybrid power sources with fuel cell for vehicle applications, power electronics, and energy management.

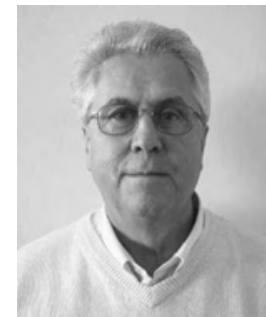

Gérard Rojat was born in Caraman, France, in 1946. $\mathrm{He}$ received the Master's and Ph.D. degrees from the University Paul Sabatier, Toulouse, France, in 1971 and 1974, respectively, and the Ph.D. degree in electrical engineering from the Université Lyon 1, Villeurbanne, France.

He was an Assistant Professor at the Ecole Centrale de Lyon for 23 years. He is currently a Senior Professor at the Université Lyon 1. He has authored or coauthored more than 100 scientific papers. 